\title{
ГЕОИНФОРМАЦИОННЫЙ АНАЛИЗ РАСПОЛОЖЕНИЯ СУЩЕСТВУЮЩИХ МЕСТ (ПЛОЩАДОК) НАКОПЛЕНИЯ ТВЕРДЫХ КОММУНАЛЬНЫХ ОТХОДОВ НА ТЕРРИТОРИИ ГОРОДА НОВОСИБИРСКА
}

\section{Мария Игоревна Панасюгина}

Сибирский государственный университет геосистем и технологий, 630108, Россия, г. Новосибирск, ул. Плахотного, 10, обучающийся, тел. (913)777-98-07, e-mail: panasyugina-mi2016@sgugit.ru

\section{Анатолий Викторович Ериов}

Сибирский государственный университет геосистем и технологий, 630108, Россия, г. Новосибирск, ул. Плахотного, 10, кандидат технических наук, доцент кафедры кадастра и территориального планирования, тел. (961)845-44-09, e-mail: er-tos@inbox.ru

\section{Алексей Викторович Дубровский}

Сибирский государственный университет геосистем и технологий, 630108, Россия, г. Новосибирск, ул. Плахотного, 10, кандидат технических наук, зав. кафедрой кадастра и территориального планирования, тел. (383)361-01-09, e-mail: avd5@ssga.ru

В статье описываются работы по интеграции в геоинформационную среду информации о существующих местах (площадках) накопления твердых коммунальных отходов (ТКО) на территории города Новосибирск для целей планирования расположений новых мест (площадкок) накопления ТКО. Выполнен сбор информации о местах (площадках) накопления ТКО, проведен анализ расположения мест (площадок) накопления ТКО и определена принадлежность территории, на коротой расположенны данные объекты.

Ключевые слова: геоинформационный анализ, места (площадки) накопления твердых коммунальных отходов, земельные участки

\section{GEOINFORMATION ANALYSIS OF EXISTING LOCATION OF MUNICIPAL SOLID WASTE STORAGE PLACES (SITES) IN THE CITY OF NOVOSIBIRSK}

\section{Maria I. Panasyugina}

Siberian State University of Geosystems and Technologies, 10, Plakhotnogo St., Novosibirsk, 630108, Russia, Student, phone: (913)777-98-07, e-mail: panasyugina-mi2016@sgugit.ru

\section{Anatoly V. Ershov}

Siberian State University of Geosystems and Technologies, 10, Plakhotnogo St., Novosibirsk, 630108, Russia, Ph. D., Associate Professor, Department of Cadastre and Territorial Planning, phone: (961)845-44-09, e-mail: er-tos@inbox.ru

\section{Alexey V. Dubrovsky}

Siberian State University of Geosystems and Technologies, 10, Plakhotnogo St., Novosibirsk, 630108, Russia, Ph. D., Head of the Department of Cadastre and Territorial Planning, phone: (383)361-01-09, e-mail: avd5@ssga.ru 
The article describes the work on integration into the geographic information environment of information about existing places (sites) of municipal solid waste accumulation (MSW) in the city of Novosibirsk for the purpose of determining the need for new places (sites) of MSW accumulation and their design. Information on MSW accumulation places (sites) was collected, the location of MSW accumulation places (sites) was analyzed and the ownership of the territory on which these objects are located was determined.

Keywords: geoinformational analysis, places (sites) of solid municipal waste accumulation, land plots, cadastre division

Актуальность данной темы исследования обусловлена тем, что в соответствии с Федеральным законом от 31.12.2017 № 503-Ф3 «О внесении изменений в Федеральный закон «Об отходах производства и потребления» и отдельные законодательные акты Российской Федерации» [9] органы местного самоуправления городских округов в области обращения с твердыми коммунальными отходами обязаны определить схемы размещения мест (площадок) накопления твердых коммунальных отходов (ТКО) [4] и осуществлять ведение реестра мест (площадок) накопления твердых коммунальных отходов (ТКО) и осуществлять ведение реестра мест (площадок) накопления твердых коммунальных отходов [5].

Определение мест расположения новых площадок накопления ТКО является важной инженерной задачей, поскольку от выбора оптимального места расположения места (площадки) [3] будет зависеть как общий объем собираемых и вывозимых с территории частного сектора ТКО, так и экологическая обстановка на территории. Кроме того, оптимальное проектирование мест расположения площадок накопления ТКО направлено на рациональное использование земельных ресурсов муниципального образования [6]. Выбор земельных участков для размещения площадок [1] накопления ТКО - это сложная многокомпонентная задача, для решения которой необходимо применение геоинформационных систем, позволяющих выполнять пространственный анализ и геомоделирование [8].

Целью исследования является выполнение геоинформационного анализа на основе интеграции в геоинформационную среду информации о существующих местах (площадках) накопления ТКО на территории города Новосибирск.

Первый этап работы заключался в сборе необходимой информации о местах (площадах) накопления ТКО. По результатам сбора информации был сформирован реестр в формате Excel, содержащий сведения о 7686 местах (площадах) накопления ТКО, включая их простанственное положение [2].

Второй этап работы заключался в геокодировании информации о существующих местах (площадках) накопления ТКО. Для проведения процедуры геокодирования была разработана идентичная реестру геоинформационная база данных в геоинформационной системе MapInfo Professional (рис. 1). 


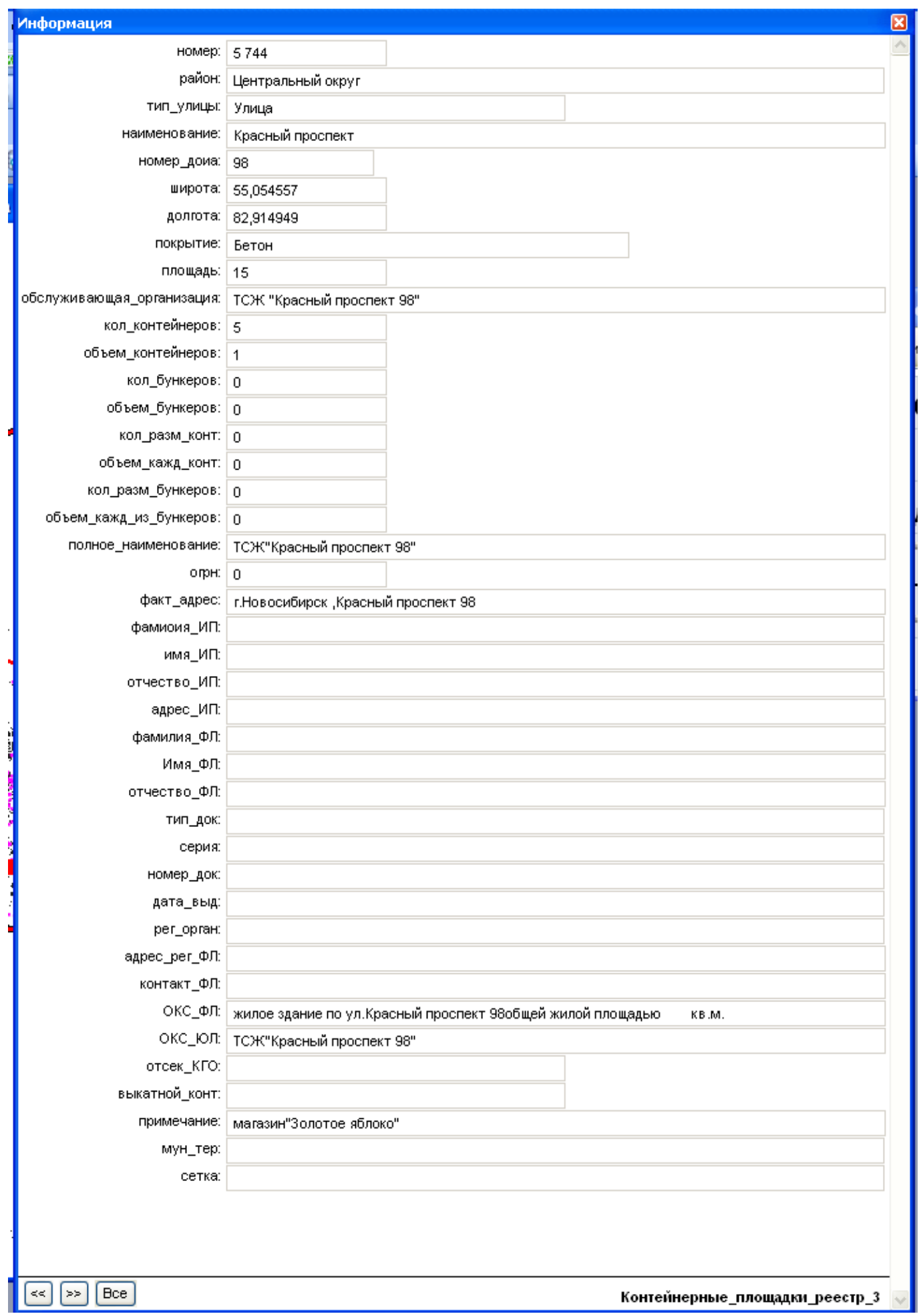

Рис. 1. Геоинформационная база данных мест (площадок) накопления ТКО

Далее информация из реестра в формате Excel была перенесена копированием в созданную геоинформационную базу данных.

Для создания точечных объектов центроидов мест (площадок) накопления ТКО была использована функция «Создание точечных объектов», алгоритм работы которой показан на рис. 2. 


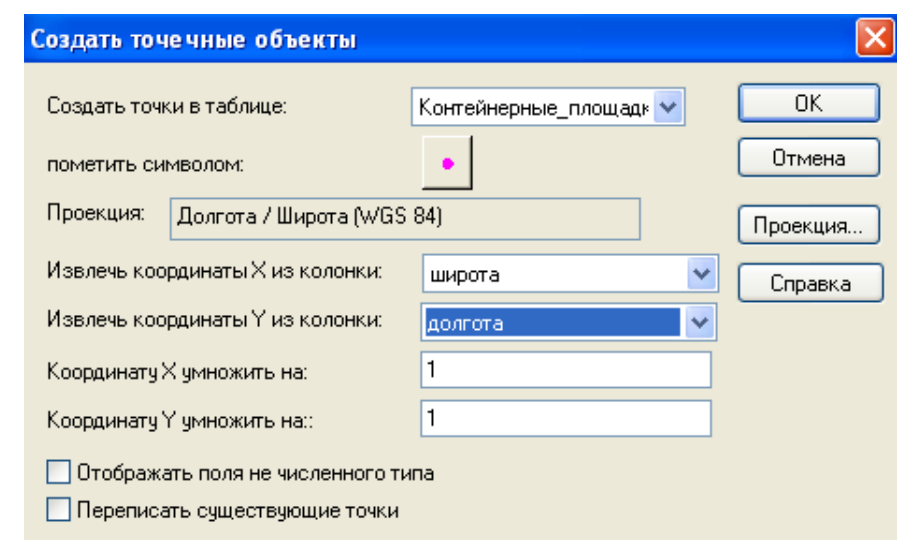

Рис. 2. Создание точечных объектов центроидов мест (площадок) накопления ТКО

В результате выполнения геокодирования создан слой точечных объектов, расположенных в местах нахождения ПНТКО. Картографическая визуализация ПНТКО представлена на рис. 3.

В качестве дополнительных информационных слоев были использованы слои: «граница города Новосибирск», «Границы районов города Новосибирск», «Здания города Новосибирск». Данные слои переданы заказчику работ в качестве дополнительного информационного обеспечения проекта.

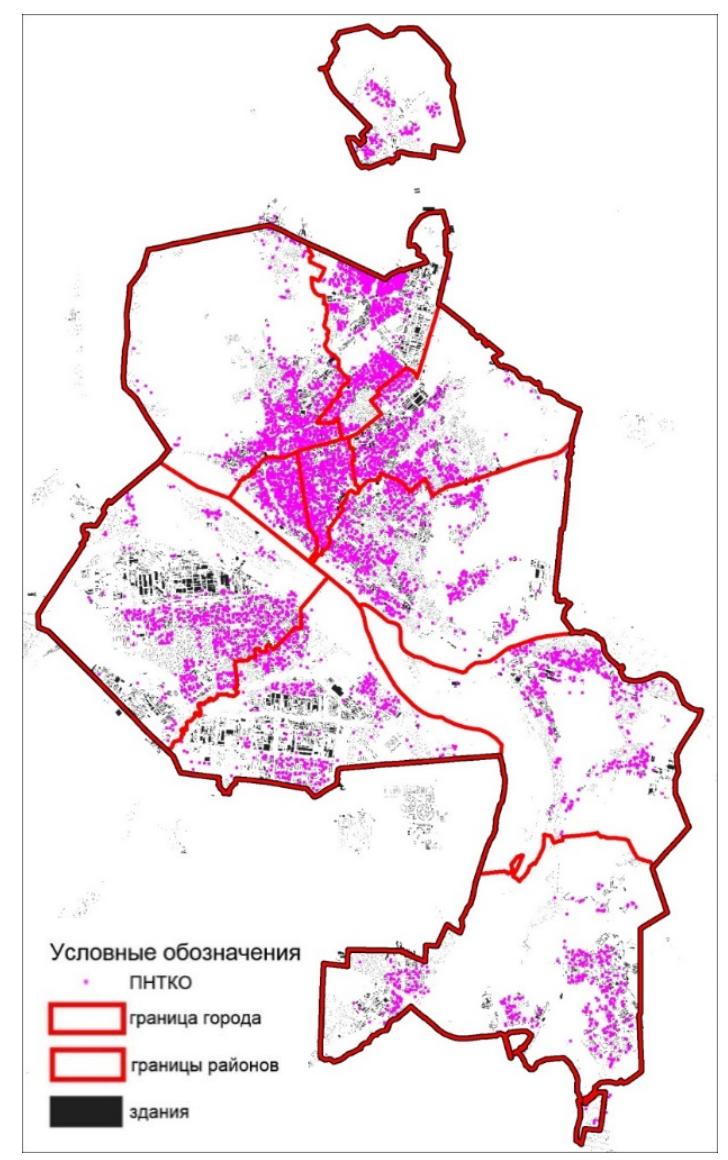

Рис. 3. Картографическая визуализация мест (площадок) накопления ТКО 
Третий этап работы заключался в определении принадлежности территорий, на которых расположены места (площадки) накопления ТКО [7]. Для этой цели были использованы данные кадастрового деления Росреестра на территорию города Новосибирск. Результат совмещения кадастрового деления и мест (площадок) накопления ТКО представлен на рис. 4.

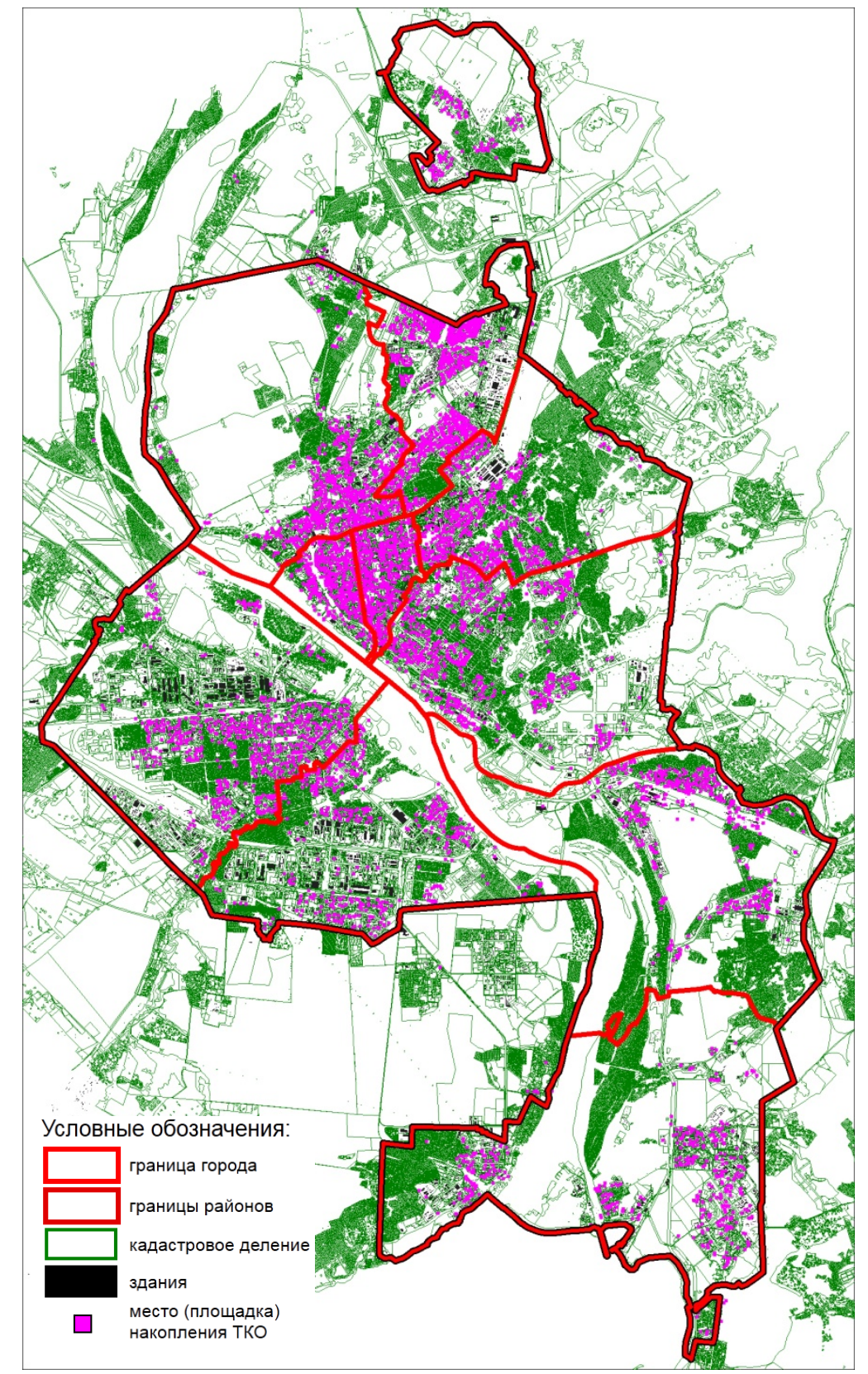

Рис. 4. Результат совмещения кадастрового деления и мест (площадок) накопления ТКО

Таким образом, в результате исследования выполнен геоинформационный анализ расположения мест (площадок) накопления твердых коммунальных отходов на территории города Новосибирск. [10] 
Решены следующие задачи:

- выполнен сбор информации о пространственном положении (мест) площадок накопления твердых коммунальных отходов;

- выполнена интеграция информации о пространственном положении площадок накопления твердых коммунальных отходов с данными кадастрового плана территории;

- определена принадлежность территории, на которой расположенны (места) площадки накопления твердых коммунальных отходов.

Полученные результаты работы в дальнейших исследованиях планируется применить для определения потребности города в новых местах (площадах) накопления ТКО и выбора земельных участков для их проектирования.

\section{БИБЛИОГРАФИЧЕСКИЙ СПИСОК}

1. Земельный кодекс Российской Федерации (ЗК РФ) от 25.10.2001 N 136-ФЗ (ред. от 15.10.2020) [Электронный pecypc]. - Режим доступа: http://www.consultant.ru/document/cons_doc_LAW_33773/._- Загл. с экрана.

2. Трубина Л.К., Авругев Е.И., Николаева О.Н. и др. Подходы к созданию геоинформационных моделей городских территорий для учета экологической. - Известия Томского политехнического университета. Инжиниринг георесурсов. 2018. Т. 329. № 9. 43-51.

3. Национальный проект «Экология». [Электронный ресурс]. - Режим доступа: https://muob.ru/aktualno/news/novosti-poseleniy/939729.html.

4. Об утверждении перечня видов объектов, размещение которых может осуществляться на землях или земельных участках, находящихся в государственной или муниципальной собственности, без предоставления земельных участков и установления сервитутов (с изменениями и дополнениями) [Электронный ресурс] : Постановление Правительства РФ от от 3 де$\begin{array}{lllllllll}\text { кабря } 2014 & \text { г. } & \mathrm{N} & 1300 & \text { (ред. от 30.04.2016) } & -\end{array}$ http://www.consultant.ru/document/cons_doc_LAW_171925/92d969e26a4326c5d02fa79b8f9cf499 4еe5633b/. - Загл. с экрана.

5. Об отходах производства и потребления [Электронный ресурс] : федер. закон от 24.06.1998 N 89-Ф3 (ред. от 01.01.2016) // СПС «КонсультантПлюс».

6. Об охране окружающей среды потребления [Электронный ресурс] : федер. закон от 10.01.2002 N 7-Ф3 (последняя редакция) // СПС «КонсультантПлюс».

7. Об утверждении Правил выдачи разрешения на использование земель или земельного участка, находящихся в государственной или муниципальной собственности [Электронный ресурс] : Постановление Правительства РФ от 27.11.2014 N 1244 (ред. от 30.07.2020) // СПС «КонсультантПлюс».

8. Об утверждении требований к составу и содержанию территориальных схем обращения с отходами, в том числе с твердыми коммунальными отходами [Электронный ресурс] : Постановление Правительства РФ от 16 марта 2016 г. N 197 // СПС «КонсультантПлюс».

9. О внесении изменений в Федеральный закон «Об отходах производства и потребления» и отдельные законодательные акты Российской Федерации [Электронный ресурс] : федер. закон от 31.12.17 № 503-ФЗ // СПС «КонсультантПлюс».

10. Об утверждении генеральной схемы очистки территории города Новосибирска [Электронный ресурс] : Постановление мэрии города Новосибирска от 17 мая 2010 г. N 137 // СПС «КонсультантПлюс».

() М. И. Панасюгина, А. В. Ершов, А. В. Дубровский, 2021 